\title{
Solitary Liver Metastasis from Follicular Variant Papillary Thyroid Carcinoma: A Case Report
}

\author{
Rahima Perveen, Jasmin Ferdous, Sharmin Quddus, Tapati Mandal \\ National Institute of Nuclear Medicine and Allied Sciences (NINMAS), Dhaka, Bangladesh \\ Correspondence Address: Dr. Rahima Perveen, Senior Medical Officer, National Institute of Nuclear Medicine \&Allied Sciences \\ (NINMAS),Block-D, BSMMU Campus, Shahbag, Dhaka-1000. Bangladesh. Email:rahimaperveen1974@gmail.com
}

\begin{abstract}
Papillary and follicular thyroid carcinomas, together known as differentiated thyroid carcinomas (DTC), are among the most curable of cancers. Distant metastases are rare events at the onset of DTC. Sites of metastases from follicular thyroid cancer (FTC) are usually osseous, and those from papillary thyroid cancer (PTC) metastasize to regional nodal basins and the lungs. Visceral metastases are rare, but the involvement of multiple sites has been reported so far. Liver metastases from differentiated thyroid carcinoma (LMDTC) are rare.We present the case of a patient with follicular variant of papillary thyroid carcinoma (FVPTC) unusually involving the liver.
\end{abstract}

Key words: Differentiated thyroid carcinoma, Solitary liver metastasis, Rare thyroid metastases.

Bangladesh J. Nucl. Med. Vol. 22 No. 2 July 2019

Doi: https://doi.org/10.3329/bjnm.v22i2.51768

\section{INTRODUCTION}

Differentiated thyroid carcinoma (DTC), encircling follicular and papillary carcinomas, has good prognosis and long-term survival rates. In reality, $80-95 \%$ of the patients survive at least 10 -years (1). DTC are relatively rare despite the common frequency of thyroid nodules (2). The prevalence of distant metastases at the time of the initial presentation of DTC is $4 \%$. During the treatment period and follow-up, the prevalence of distant metastases ranges from $2 \%$ in low-risk patients to $33 \%$ in high-risk patients. Distant metastases occur primarily in the lungs than in the bones. The prognosis of distant metastases is usually bad with poor outcomes. Only $50 \%$ of patients endure ten years after a diagnosis of the metastatic DTC (3-5). The median age at diagnosis is $45-50$ years, with two to four times more frequent in women than men (6). However, the prognosis of the patients at higher risk for recurrent disease or even death depends on the age at diagnosis, stage, capsular involvement, nodal involvement, size, and histological type. Liver metastasis from thyroid cancer is a very rare event with a reported frequency of less than $0.5 \%$ (7). Metastatic liver disease from both follicular and papillary thyroid cancer is always multiple or diffuse and is usually associated with other hematogenous metastases inthe lungs, bones, and the brain (8-16). Survival ranges from 1 to 60 months after the diagnosisof LMDTC. (1)

\section{CASE REPORT}

An otherwise healthy, 72 years old female presented with swellings of the right side and middle of neck 7 years back. Suddenly she noticed a swelling in the right hypochondriac region of the abdomen, which gradually increased in size within 1 year. The patient had no cardiac, pulmonary, or renal diseases. There was no history of hepatitis, tuberculosis, diabetes or exposure to radiation.

\section{INVESTIGATIONS AND TREATMENT}

A high-resolution ultrasound scan (HRUS) of the neck revealed a multinodular goiter with bilateral enlarged cervical lymph nodes. The biggest neck node in the right measured $2.5 \times 1.2 \mathrm{~cm}$ and that of the left $1.7 \times 0.6 \mathrm{~cm}$. Fine needle aspiration cytology (FNAC) primarily diagnosed FVPTC, and after total thyroidectomy,it was histopathologically confirmed. The patient neglected her visit to Nuclear Medicine (NM) and received no radioactive iodine therapy (RAIT). After almost 7 years, she reported again. We performed HRUS of the neck and whole abdomen due to painful, hard, slowly growing swelling in the right hypochondriac region of her abdomen. HRUS of the neck revealed multiple enlarged lymph nodes in both sides of the neck which sizes are increased in size compared to the previous scan.

The whole abdomen ultrasound revealed a reasonably large $(6.2$ X $6.0 \mathrm{~cm})$, irregular shaped, solid, echogenic mass lesion in the antero-inferior aspect occupyingthe segments $\mathrm{V}$ and VIof the right lobe of the liver. 
Computed tomography (CT) of the abdomen showed a big, hypodense area $(7 \times 6 \times 5 \mathrm{~cm})$ in the right lobe of the liver located in segments $\mathrm{V} \& \mathrm{VI}$ and provisionally diagnosed as a case of hepatocellular carcinoma (HCC).

Ultrasound-guided fine-needle aspiration (FNA) from liver SOL cytologically confirmed papillary thyroid cancer with metastases in the liver. The patient was referred to the National Institute of Nuclear Medicine \& Allied Sciences (NINMAS) for radioactive iodine ablation therapy (RAIT) with a high level of pre-therapy serum thyroglobulin (Tg) level $(>300 \mathrm{ng} / \mathrm{ml})$ and a high anti-Tg antibody level of
$205 \mathrm{U} / \mathrm{ml}$. Ablation therapy was done with administration of $150 \mathrm{mCi}$ I131 $(5550 \mathrm{Mbq})$ at NINMAS with proper isolation and radiation safety measures. Post therapy whole-body scan $\left(\mathrm{R}_{\mathrm{X}} \mathrm{WBS}\right)$ showed intense radio-iodine uptake in thyroid bed and right lobe of the liver suggesting iodine avidity of the solitary metastatic lesion in the liver. Post therapeutic routine follow-up will be done after 3 months. As the lesion was iodine avid, so our plan was to repeat RAIT prefer ably after surgical resection of the liver mass preferably if possible. But the patient was lost and proper follow up could not be done.
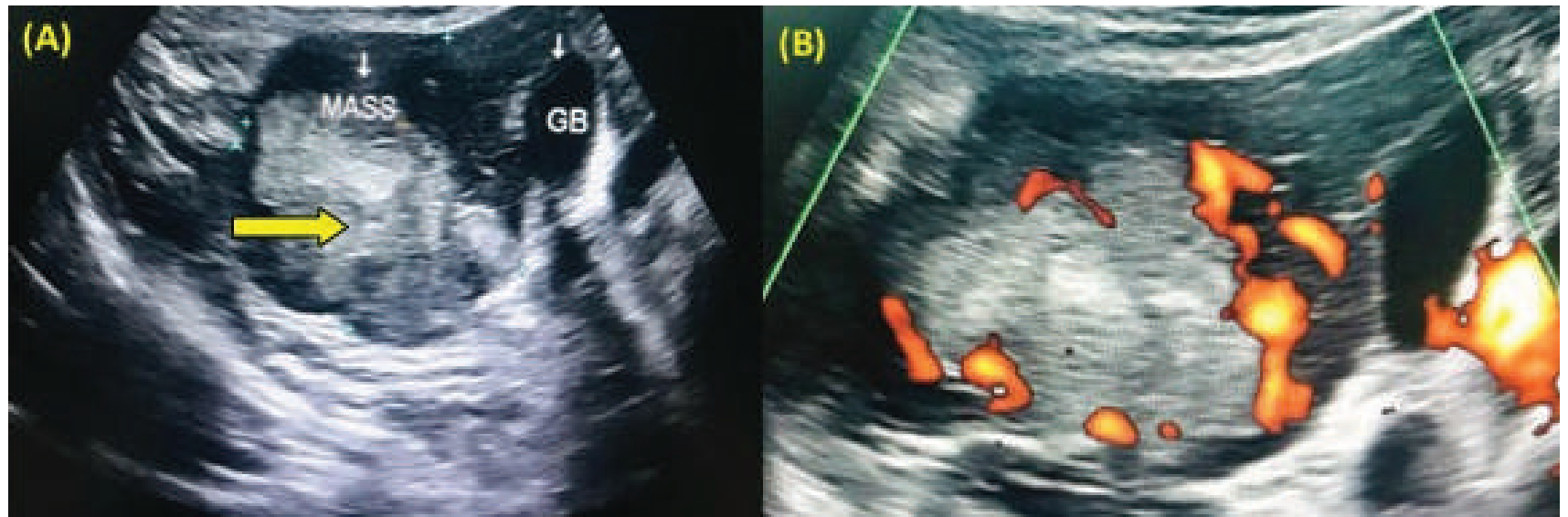

Figure 1: Ultrasound image of a 72 Y/O, female patient showing (A) Big heterogenous mass (yellow arrow) lesion in right lobe of liver measuring about $6.2 X 6.0 \mathrm{~cm}$. (B): Doppler flow shows increased vascularity within the mass.

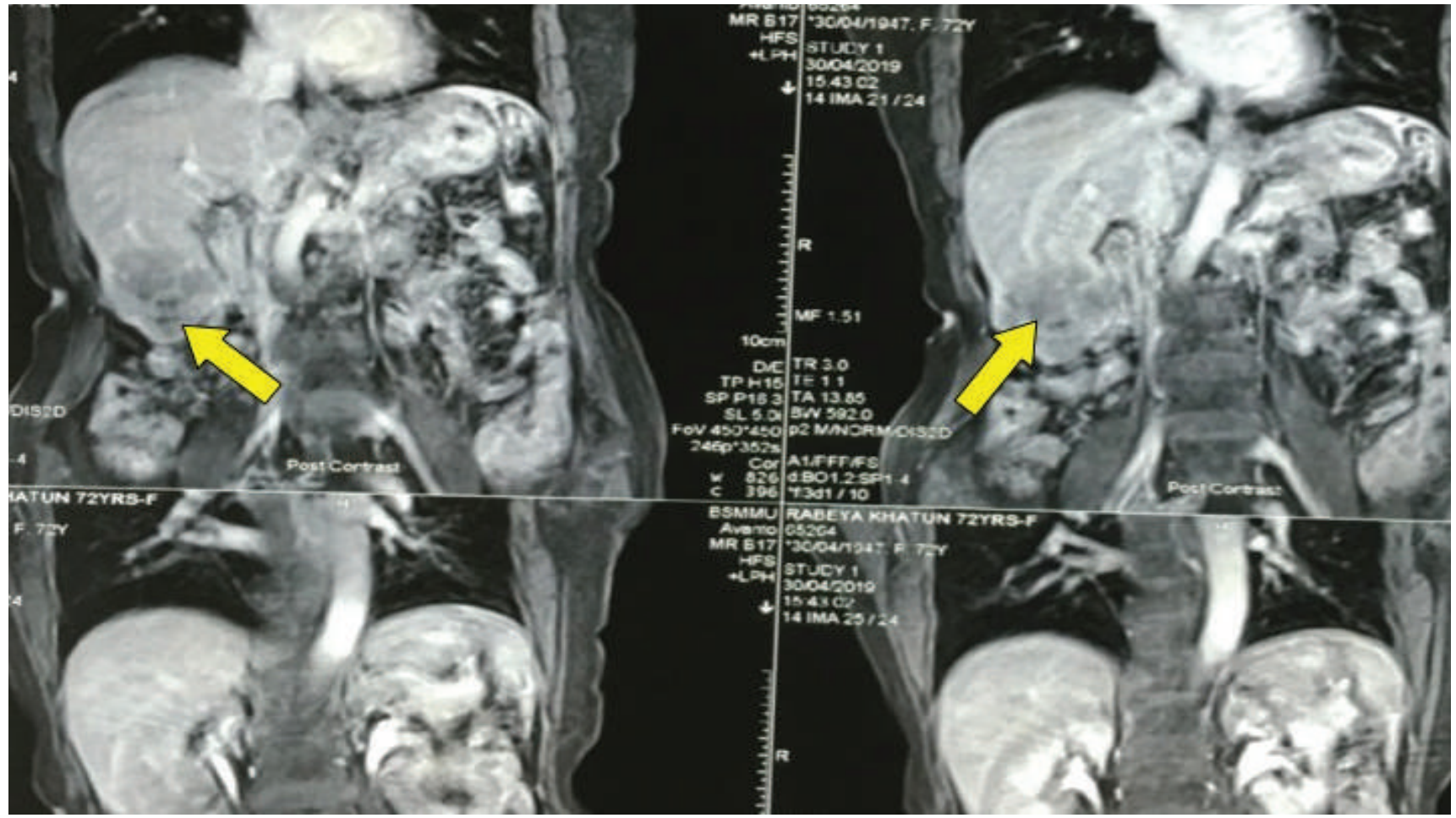

Figure 2: Computed tomogralhy image of the mass lesion (yellow arrow) in segment $\mathrm{V}$ and $\mathrm{VI}$ of right lobe of liver. 


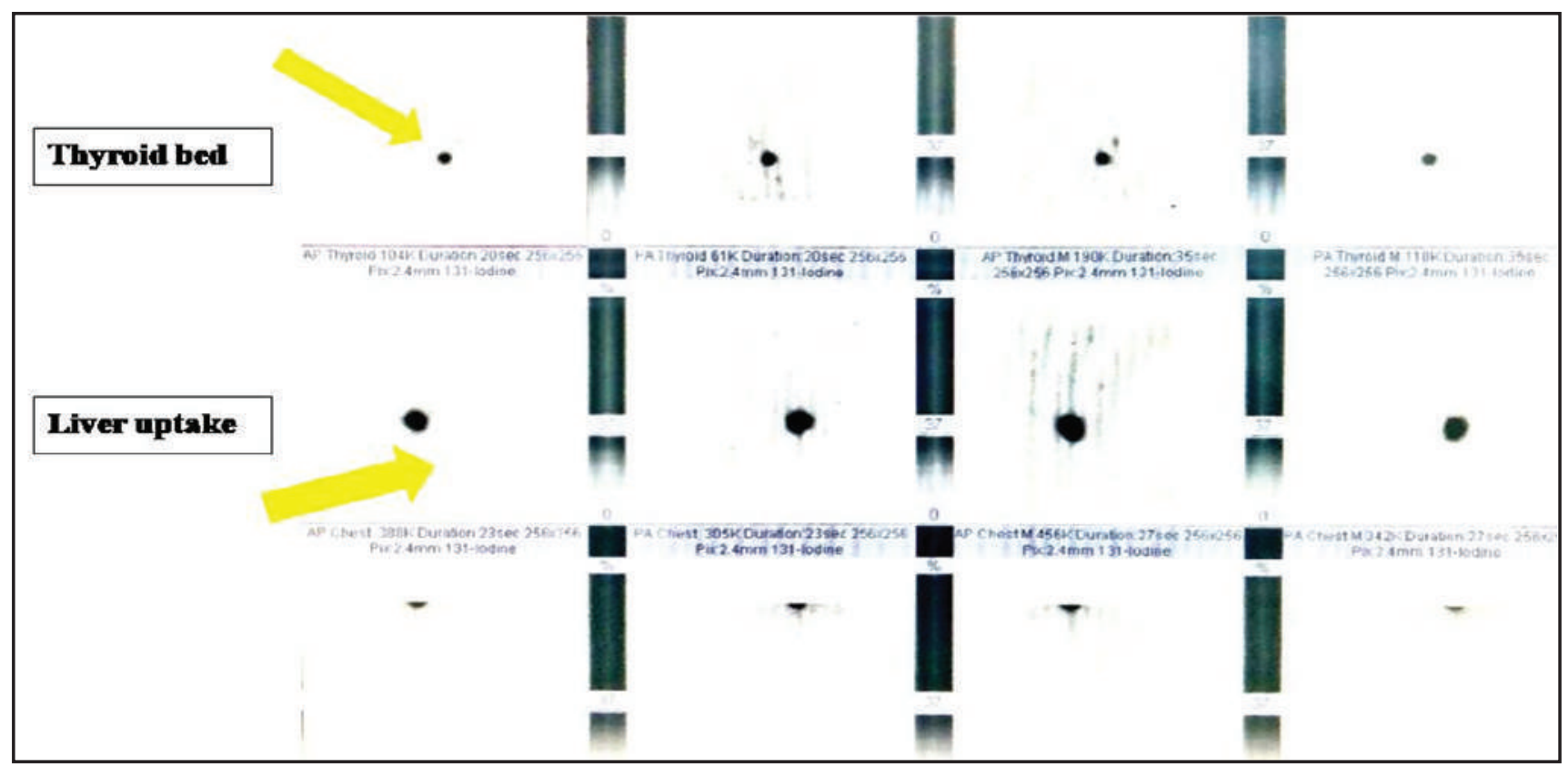

Figure 3: Whole-body 131I post-therapy scan shows radio-iodine uptake in thyroid bed and right lobe of liver (yellow arrow).

\section{DISCUSSION}

The outcome of the well-differentiated thyroid carcinoma (WDTC) usually has a good outcome, but patients presenting with distant metastatic disease have less favorable outcomes. For this reason, many risk stratification algorithms are considered to be of high risk (18-21). Although the higher possibility of poor outcomes, recent treatment strategy advocates an aggressive approach in management with surgery and postoperative RAIT (20-23). Treatment consists of total thyroidectomy, neck dissection as indicated by the disease, followed by RAIT in the majority of patients. Distant metastases occur in up to $10 \%$ of the brain, eye, breast, liver, kidney, muscle, skin area are unusual (24). LMDTC from DTC is relatively rere, with a reported frequency of $0.5 \%$ (7). Metastatic liver involvement from DTC is nearly always multiple or diffuse and is usually found along witho ther distant metastases (lung, bone, and brain) (8-16).

Only ten cases have been documented in the literature; three were males and seven were females, with an average age of about 63 years (range: 32-85 years). Histologically, the primary tumor was identified as papillary in four patients, follicular in five patients, and Hurthle cell thyroid cancer in one patient.

Liver masses can be detected by various imaging modalities, such as ultrasonography and CT, and are
usually131I negative. 131I-positive metastases are extremely rare. DTC liver metastasis has a poor prognosis. Surgical resection of liver lesions has been reported to offer the best chance for prolonged survival (24).

Most liver metastases from DTC are asymptomatic and usually revealed incidentally. This reported female patient had no definite complaint except swelling of the neck. HRUS proved multinodular goiter and bilateral enlarged cervical lymph nodes only could convince her for total thyroidectomy but neither follow up nor RAIT for histologically proven FVPTC was her choice and negligience. As an unfortunate sequel, she presented with a liver mass 7 years later which was cytologically proven as a solitary liver metastatic lesion from papillary thyroid cancer and high serum $\operatorname{Tg}(>300 \mathrm{ng} / \mathrm{ml})$. Even after explaining the benefits of surgical resection followed by RAIT as there is chance of prolonged survival (25), the patient refused metastatectomy of liver in this case and opted for RAIT with $150 \mathrm{mCi} 131 \mathrm{I}$. Unusual intense liver uptake of 131 in RxWBS was also a rare phenomenon in this case.

Kondo et al. (15) reported a case of a 48-year-old Japanese woman who was operated (subtotal thyroidectomy) for follicular adenoma of her thyroid. Eight years after theinitial surgery, an isolated liver lesion was incidentally detected on abdominal CT. On histological examination, the nodule was entirely composed of 
small to large follicles containing colloid material. Thus she was diagnosed to have had minimally invasive follicular carcinoma with secondary isolated liver metastasis. The symptoms of the patient of our case had much similarities with their findings.

Kouso et al. (26) reported a case of follicular thyroid carcinomain in a 73-year-old woman who had undergone curative resection of thyroid carcinoma 32 years earlier. CT of her abdomen revealed a round lesion, approximately $1.5 \mathrm{~cm}$ in diameter. She underwent laparotomy and partial resection of her liver. Histologicall diagnosis was a metastatic liver cancer from thyroidfollicular carcinoma.

\section{CONCLUSION}

The 131I WBS, combined with HRUS and CT scan, plays an important role in increasing diagnostic accuracy, reducing pitfalls, and modifying therapeutic strategies.

\section{REFERENCES}

1. Brient C, Mucci S, Taïb D, Mathonnet M, Menegaux F, Mirallié E, Meyer P, Sebag F, Triponez F, Hamy A. Differentiated thyroid cancer with liver metastases: lessons learned from managing a series of 14 patients. International Surgery. 2015 Mar;100(3):490-6.

2. M. Keeston Jones, Management of papillary and follicular thyroid cancer, J. R.Soc Med. 2002 Jul;95(7):325-6.

3. Mizukami Y, Michigishi T, Nonomura A, Hashimoto T, Terahata S, Noguchi M, Hisada KI, Matsubara F. Distant metastases in differentiated thyroid carcinomas: a clinical and pathologic study. Human pathology. 1990 Mar 1;21(3):283-90.

4. Tubiana M, Schlumberger M, Rougier P, Laplanche A, Benhamou E, Gardet P, Caillou B, Travagli JP, Parmentier C. Long-term results and prognostic factors in patients with differentiated thyroid carcinoma. Cancer. 1985 Feb 15;55(4):794-804

5. Johnson MW, Morettin LB, Sarles HE, Zaharopoulos P. Follicular carcinoma of the thyroid metastatic to the kidney 37 years after resection of the primary tumor. The Journal of Urology. 1982 Jan;127(1):114-6.

6. Schlumberger MJ. Papillary and follicular thyroid carcinoma. New england journal of medicine. 1998 Jan 29;338(5):297-306.

7. Salvatori M, Perotti G, Rufini V, Maussier ML, Summaria V, Fadda G, Troncone L. Solitary liver metastasis from Hürthle cell thyroid cancer: a case report and review of the literature. Journal of endocrinological investigation. 2004 Jan 1;27(1):52-6.

8. Bakheet SM, Powe J, Hammami MM, Amin TM, Akhtar M, Ahmed M. Isolated porta hepatis metastasis of papillary thyroid cancer. Journal of Nuclear Medicine. 1996 Jun 1;37(6):993-4.

9. Tur GE, Asanuma Y, Sato T, Kotanagi H, Sageshima M, Yong-Jie Z, Koyama K. Resection of metastatic thyroid carcinomas to the liver and the kidney: report of a case. Surgery today. 1994 Sep 1;24(9):844-8.

10. Tur GE, Asanuma Y, Sato T, Kotanagi H, Sageshima M, Yong-Jie Z, Koyama K. Resection of metastatic thyroid carcinomas to the liver and the kidney: report of a case. Surgery today. 1994 Sep 1;24(9):844-8.
11. Malhotra G, Upadhye TS, Sridhar E, Asopa RV, Garde PS, Gawde S, Rangarajan $\mathrm{V}$. Unusual case of adrenal and renal metastases from papillary carcinoma of thyroid. Clinical nuclear medicine. 2010 Sep 1;35(9):731-6.

12. Niederle BR, Roka R, Schemper M, Fritsch A, Weissel M, Ramach W. Surgical treatment of distant metastases in differentiated thyroid cancer: indication and results. Surgery. 1986 Dec;100(6):1088-97.

13. Young RH. Ovarian metastasis from thyroid carcinoma twelve years after partial thyroidectomy mimicking strumaovarii report of a case. Int. J. Gynecol. Pathol.. 1993;12:333-43.

14. Guglielmi R, Pacella CM, Dottorini ME, Bizzarri GC, Todino V, Crescenzi A, Rinaldi R, Panunzi C, Rossi Z, Colombo L, Papini E. Severe thyrotoxicosis due to hyperfunctioning liver metastasis from follicular carcinoma: treatment with $131 \mathrm{I}$ and interstitial laser ablation. Thyroid. 1999 Feb;9(2):173-7.

15. Kondo $\mathrm{T}$, Katoh R, Omata $\mathrm{K}$, Oyama $\mathrm{T}$, Yagawa A, Kawaoi A. Incidentally detected liver metastasis of well-differentiated follicular carcinoma of the thyroid, mimicking ectopic thyroid. Pathology international. 2000 Jun;50(6):509-13.

16. Kelessis NG, Evangelos PP, Dimitra DV, Nikiforos AA, Angeliki TP, Pericles VP. Unusual metastatic spread of follicular thyroid carcinoma: report of a case. Surgery today. $2005 \mathrm{Apr}$ 1;35(4):300-3.

17. Shah DH, Samuel AM. Metastasis to the liver in well-differentiated carcinoma of the thyroid. Thyroid. 1996 Dec;6(6):607-11.

18. Shaha AR, Shah JP, Loree TR. Risk group stratification and prognostic factors in papillary carcinoma of thyroid. Annals of surgical oncology. 1996 Nov 1;3(6):534-8.

19. Hay ID, Bergstralh EJ, Goellner JR, Ebersold JR, Grant CS. Predicting outcome in papillary thyroid carcinoma: development of a reliable prognostic scoring system in a cohort of 1779 patients surgically treated at one institution during 1940 through 1989. Surgery. 1993 Dec 1;114(6):1050-8.

20. Cooper, D.S., Doherty, G.M., Haugen, B.R., Kloos, R.T., Lee, S.L., Mandel, S.J., Mazzaferri, E.L., McIver, B., Pacini, F., Schlumberger, M. and Sherman, S.I., 2009. Revised American Thyroid Association management guidelines for patients with thyroid nodules and differentiated thyroid cancer: the American Thyroid Association (ATA) guidelines taskforce on thyroid nodules and differentiated thyroid cancer. Thyroid, 19(11), pp.1167-1214.

21. Cady B, Rossi R. An expanded view of risk-group definition in differentiated thyroid carcinoma. Surgery. 1988 Dec 1;104(6):947-53.

22. Watkinson JC. The British Thyroid Association guidelines for the management of thyroid cancer in adults. Nuclear medicine communications. 2004 Sep 1;25(9):897-900.

23. Pacini F, Schlumberger M, Dralle H, Ilisea R, Smith Y, Viersinga V. European consensus on the management of patients with differentiated carcinoma of the thyroid from follicular epithelium. Vestnikkhirurgiiimeni II Grekova. 2008;167(1):52-6.

24. Djenic B, Duick D, Newell JO, Demeure MJ. Solitary liver metastasis from follicular variant papillary thyroid carcinoma: A case report and literature review. International Journal of Surgery Case Reports. 2015 Jan $1 ; 6: 146-9$

25. Niederle BR, Roka R, Schemper M, Fritsch A, Weissel M, Ramach W. Surgical treatment of distant metastases in differentiated thyroid cancer: indication and results. Surgery. 1986 Dec;100(6):1088-97.

26. Kouso H, Ikegami T, Ezaki T, Ishida T, Aimitsu S, Fujihara M, Mori M. Livermetastasis from thyroid carcinoma 32 years after resection of the primary tumor: report of a case. Surg Today. 2005;35(6):480-2. 